\title{
Thermal and Mechanical Properties of Cement Mortar Composite Containing Recycled Expanded Glass Aggregate and Nano Titanium Dioxide
}

\author{
Ali Yousefi ${ }^{1}{ }^{\mathbb{D}}$, Waiching Tang ${ }^{1, *(\mathbb{D}}$, Mehrnoush Khavarian ${ }^{1}$, Cheng Fang ${ }^{2}$ and Shanyong Wang ${ }^{3}$ \\ 1 School of Architecture and Built Environment, University of Newcastle, Callaghan, NSW 2308, Australia; \\ ali.yousefi@newcastle.edu.au (A.Y.); mehrnoush.khavarian@newcastle.edu.au (M.K.) \\ 2 Global Centre for Environmental Remediation (GCER), University of Newcastle, Callaghan, NSW 2308, \\ Australia; cheng.fang@newcastle.edu.au \\ 3 School of Civil Engineering, University of Newcastle, Callaghan, NSW 2308, Australia; \\ shanyong.wang@newcastle.edu.au \\ * Correspondence: patrick.tang@newcastle.edu.au; Tel.: +61-249-217-246
}

Received: 14 February 2020; Accepted: 20 March 2020; Published: 26 March 2020

\begin{abstract}
One of the growing concerns in the construction industry is energy consumption and energy efficiency in residential buildings. Moreover, management of non-degradable solid glass wastes is becoming a critical issue worldwide. Accordingly, incorporation of recycled expanded glass aggregates (EGA) as a substitution for natural fine aggregate in cement composites would be a sustainable solution in terms of energy consumption in the buildings and waste management. This experimental research aims to investigate the effects of EGA on fresh and hardened properties and thermal insulating performance of cement mortar. To enhance the mechanical properties and water resistance of the EGA-mortar, nano titanium dioxide $\left(\mathrm{nTiO}_{2}\right)$ was used as nanofillers. The results showed an increase in workability and water absorption of the EGA-mortar. In addition, a significant decrease in bulk density and compressive strength observed by incorporating EGA into the cement mortar. The EGA-mortar exhibited a low heat transfer rate and excellent thermal insulation property. Furthermore, inclusion of $\mathrm{nTiO}_{2}$ increased compressive strength and water resistance of EGA-mortar, however, their heat transfer rate was increased. The results demonstrated that EGA-mortar can be integrated into the building envelop or non-load bearing elements such as wall partition as a thermal resistance to reduce the energy consumption in residential buildings.
\end{abstract}

Keywords: industrial waste; sustainable concrete; recycled expanded glass

\section{Introduction}

In the last few decades, demand for energy consumption in the residential building has risen and there is a high intention for reducing energy consumption in the buildings. The energy efficiency of the buildings has become increasingly critical with the rising costs of energy as well as increasing awareness on global warming effects [1,2]. Furthermore, waste management has become a critical issue. In fact, non-degradable wastes such as glass are unable to break down naturally which is developing environmental problems [3]. In Australia, about 1.1 Mt of glass waste was generated in the year of 2016-2017 from that 43\% was stockpiled. In New South Wales, companies accepting the landfill levy to dump their glass waste in landfill or arranging to relocate the waste to other states where the landfill levy does not apply. Thus, use of waste glass in the large scale is a sustainable solution in terms of reduction of carbon footprint and saving the costs and energy. The construction industry is a potential sector for utilization of waste glass. In this regard, use of solid wastes for manufacturing the building materials with high thermal insulation properties is an effective approach toward sustainable 
development and decreasing the energy consumption in buildings [4-6]. It has been reported that the incorporation of insolation materials in the building can reduce the indoor temperature fluctuation up to $4{ }^{\circ} \mathrm{C}$ that would save $10-30 \%$ of energy usage [1,2].

Although many investigations have been carried out on utilizing waste glass in the form of glass powder [7-11] and glass bead [12-15] in concrete products, it has not found its position in the construction industry yet. Expanded glass aggregates (EGA), is a new commercial product, which are manufactured from waste and post-consumer glass. The EGA possess a relatively smooth surface with numerous encapsulated pores can be used as an insulating material [16]. The porous structure and low thermal conductivity of EGA can effectively reduce the heat transfer rate. The utilization of EGA in cementitious materials brings two-fold advantages, first, reducing the landfill cost and environment and secondly can reduce the energy consumption in buildings [16]. Recently, some studies [17-21] have been conducted to investigate the effect of EGA on mechanical and thermal properties of concrete and cement mortar, however, the utilization of EGA as an insulating material is at the initial stage. The great advantage of EGA is the possibility of production in a variety of size. Such a variety of particle sizes allows the improvement of the homogeneity of mixture and consequently reduces the possibility of segregation of the mixture [22].

Yu et al. [23] and Spiesz et al. [24] developed a cement-based lightweight composite using five different size of EGA (range between 0.1 and $2.0 \mathrm{~mm}$ ) and reported the density of $1280-1490 \mathrm{~kg} / \mathrm{m}^{3}$ and compressive strength of 23.3-30.2 MPa. Rumsys et al. [21] prepared cement mortar with two types of fine expanded aggregates (expanded glass and expanded clay) to compare their compressive strength and durability properties. In the mixes, they replaced the fine aggregates with expanded glass and expanded clay by the weight of the sand $(8.5,16.7,33.3,66.7$, and $100 \mathrm{wt} \%)$. The obtained results revealed that in the mixtures with $100 \%$ EGA, the density decreased about $37 \%$ and the compressive strength after 28 days of curing dropped about $60 \%$. The results also confirmed that EGA could be applied in the cementitious composites without limitation related to the alkali-silica reaction. In the experiment conducted by Namsone et al. [25], a foamed matrix was prepared using EGA and the mechanical, thermal and frost resistance properties were examined. They obtained the compressive of 4.7 and $5.7 \mathrm{MPa}$ at the age of 7 and 28 days and the thermal conductivity of $0.152-0.108 \mathrm{~W} / \mathrm{m} . \mathrm{K}$. Moreover, it was observed that reference samples had lower values of weight loss $\left(\mathrm{g} / \mathrm{m}^{2}\right)$ after the freeze-thaw test comparing to compositions with EGA. They also characterized the microstructure of the prepared foam matrix using optical microscopy and observed that EGA were distributed uniformly over the cross-section without any processes of segregation.

Abd Elrahman et al. [16] fabricated EGA-cement mortar and reported crushing resistance of $1.9-2.9 \mathrm{~N} / \mathrm{mm}^{2}$ and water absorption of $13.6-15.8 \mathrm{wt} \%$ depending on the particle size. The results showed a compressive strength of about $6 \mathrm{MPa}$ and thermal conductivity less than $0.14 \mathrm{~W} / \mathrm{m} . \mathrm{K}$. In the study conducted by [26], the influence of the grain size and percentage of EGA content on physical and mechanical properties of the cement composite were investigated. They reported an average porosity of $45-67 \%$ and bulk density of $903-1078 \mathrm{~kg} / \mathrm{m}^{3}$ in specimens containing $100 \%$ EGA with the size of 2-4 mm. Moreover, the compressive strengths of 6.68-12.49 MPa obtained for EGA cement mortar. In another attempt, [27] investigated the possibility of using artificial neural networks to design the composition of cement composite containing EGA with the desired properties. They established the relation between the quantity of EGA and the porosity, bulk density, and compressive strength of a cement composite. Moreover, previous studies revealed that high glass content (above $50 \%$ ) could considerably increase the water absorption of cementitious composites $[28,29]$. It can be concluded that incorporation of EGA in cement mortar can significantly reduce the mechanical properties such as compressive strength and water resistance of cement matrix. Hence, in order to compensate the reduction in mechanical strength and water absorption of cementitious composites integrated with EGA, nanofillers such as $\mathrm{TiO}_{2}$ can be used. Previous researches have demonstrated that the addition of $\mathrm{TiO}_{2}$ nanoparticles effectively enhanced the compressive strength and reduce the water absorption of cementitious composites [30-35]. Indeed, $\mathrm{nTiO}_{2}$ fills the nanovoids in concrete, which leads to the 
increment of compressive strength up to $40 \%[34,36]$. Moreover, $\mathrm{TiO}_{2}$ accelerates the formation of C-S-H gel by increasing the amount of crystalline $\mathrm{Ca}(\mathrm{OH})_{2}$ at the early age of hydration [32,37]. Ma et al. [32] reported $37 \%$ and $44 \%$ increase in tensile and flexural strength respectively for the samples containing $\mathrm{TiO}_{2}$. In addition, the results indicated that the addition of $\mathrm{TiO}_{2}$ could significantly refine the pores and shift them to the harmless pores. In the research conducted by Behfarnia et al. [31], it was observed that $\mathrm{TiO}_{2}$ nanoparticles decreased the permeability of the cement matrix. In the research conducted by Khushwaha et al. [34] and Sorathiya et al. [33], the effect of various proportion of $\mathrm{TiO}_{2}$ was studied. It was concluded that addition of $\mathrm{TiO}_{2}$ up to $1 \%$ could significantly enhance the mechanical properties of concrete.

This research aims to develop a cement mortar with a lower heat transfer rate and insulating properties using substitution of a natural aggregate (NA) with EGA. In this study, the effect of incorporation of EGA and $\mathrm{TiO}_{2}$ nanoparticles on workability, bulk density, water penetration, compressive strength, and heat transfer rate of the cement mortar were investigated. Infrared thermography (IRT) was used to measure the thermal insulation property of EGA cement mortar. The IRT technique has been utilized to evaluate the thermal energy storage performance of building materials in previous studies [38], however it has not been used for measuring the thermal insulating property of the EGA cement mortar. The conducted research is an additional step toward development of insulating building material and sustainable application of EGA in the construction industry.

\section{Materials and Methods}

\subsection{Materials}

The materials used in the study to fabricate cement mortar composite were ordinary Portland cement (OPC), natural aggregate (NA), recycled expanded glass aggregate (EGA), superplasticizer (SP), and nano titanium dioxide $\left(\mathrm{nTiO}_{2}\right)$. OPC from Boral Australia Co. and in accordance with AS3972 was used as a binder and Sikament NN was used as a superplasticizer (SP) in the mix, which meets all requirements as per AS1478.1 for high range water reducing admixture. EGA with a particle size of 0.25-4 mm from EGT Co. is shown in Figure 1. The specifications of EGA are compliant with EN and DIN standards. Figure 2 shows a SEM image of the utilized EGA in this study. Table 1 demonstrates the physical, mechanical, and thermal properties of the EGA.

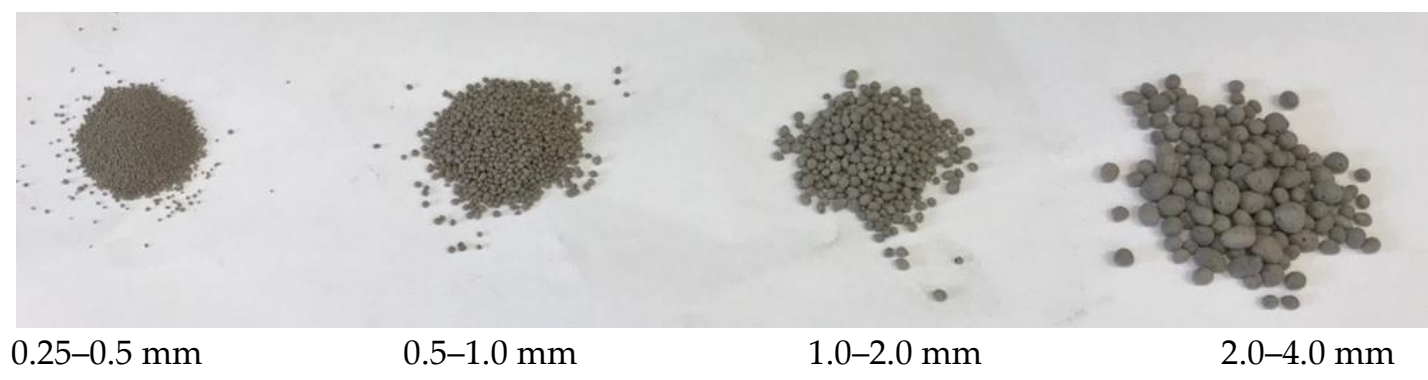

Figure 1. Expanded glass aggregate (EGA) with a different grain size.

Table 1. Physical, mechanical, and thermal properties of the EGA (Expanded Glass Technologies).

\begin{tabular}{ccccc}
\hline \multirow{2}{*}{ Property } & \multicolumn{4}{c}{ Grain Size } \\
\cline { 2 - 5 } & $\mathbf{0 . 2 5 - 0 . 5}$ & $\mathbf{0 . 5 - 1}$ & $\mathbf{1 - 2}$ & $\mathbf{2 - 4}$ \\
\hline Loose bulk density $\left(\mathrm{kg} / \mathrm{m}^{3}\right)$ & 300 & 250 & 220 & 190 \\
Particle density $\left(\mathrm{kg} / \mathrm{m}^{3}\right)$ & 540 & 450 & 350 & 310 \\
Compressive strength $(\mathrm{MPa})$ & $\geq 2.9$ & $\geq 2.6$ & $\geq 2.4$ & $\geq 2.2$ \\
Thermal conductivity $(\mathrm{W} / \mathrm{mK})$ & 0.07 & 0.07 & 0.07 & 0.07 \\
\hline
\end{tabular}




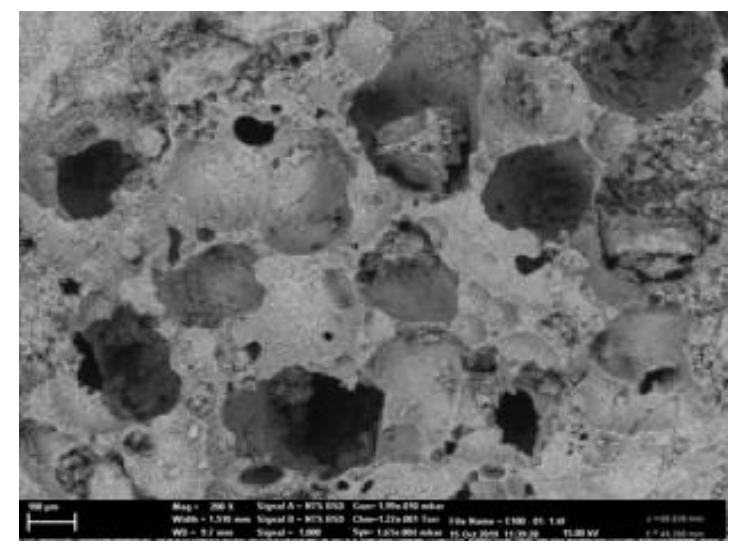

Figure 2. SEM pictures of the utilized EGA.

Crushed gravel with the maximum size of $4.0 \mathrm{~mm}$ and density of $2800 \mathrm{~kg} / \mathrm{m}^{3}$ was used as NA. The NA was subjected to the particle size distribution test to precisely replicate the distribution of NA for the replacement of EGA by volume in the cement mortar. The size distribution testing was completed in accordance with AS1012 and the results are found in Figure 3.

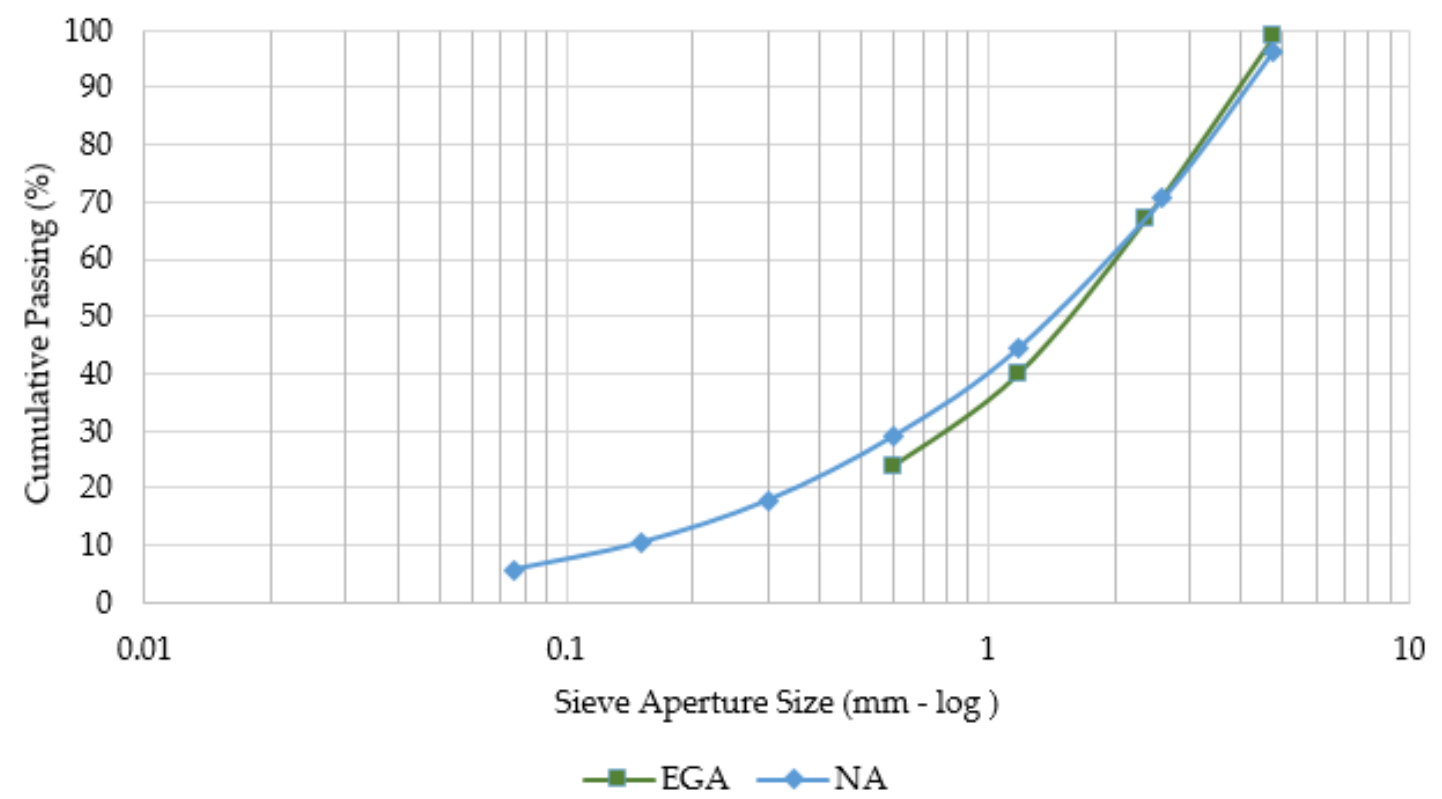

Figure 3. Size distribution of the natural aggregate and EGA.

Moreover, the mercury intrusion porosimetry (MIP) test was undertaken to measure the porosity as well as pore size distribution of the EGA. The MIP test results of the EGA are revealed in Figure 4.

Nanoparticles titanium dioxide $\left(\mathrm{nTiO}_{2}\right)$ purchased in the powder form from US Research Nanomaterials, Inc. Table 2 demonstrates the properties of the $\mathrm{nTiO}_{2}$ as indicated by the manufacturer.

Table 2. The properties of the nano-nTiO 2 (US Research Nanomaterials, Inc.).

\begin{tabular}{cc}
\hline Properties & Value \\
\hline Purity & $99.98 \%$ \\
Average Particles Size & $30(\mathrm{~nm})$ \\
Specific surface area & $50\left(\mathrm{~m}^{2} / \mathrm{g}\right)$ \\
Bulk Density & $0.42\left(\mathrm{~g} / \mathrm{cm}^{3}\right)$ \\
True Density & $\left.3.9 \mathrm{~g} / \mathrm{cm}^{3}\right)$ \\
PH & $5.5-6.5$ \\
\hline
\end{tabular}




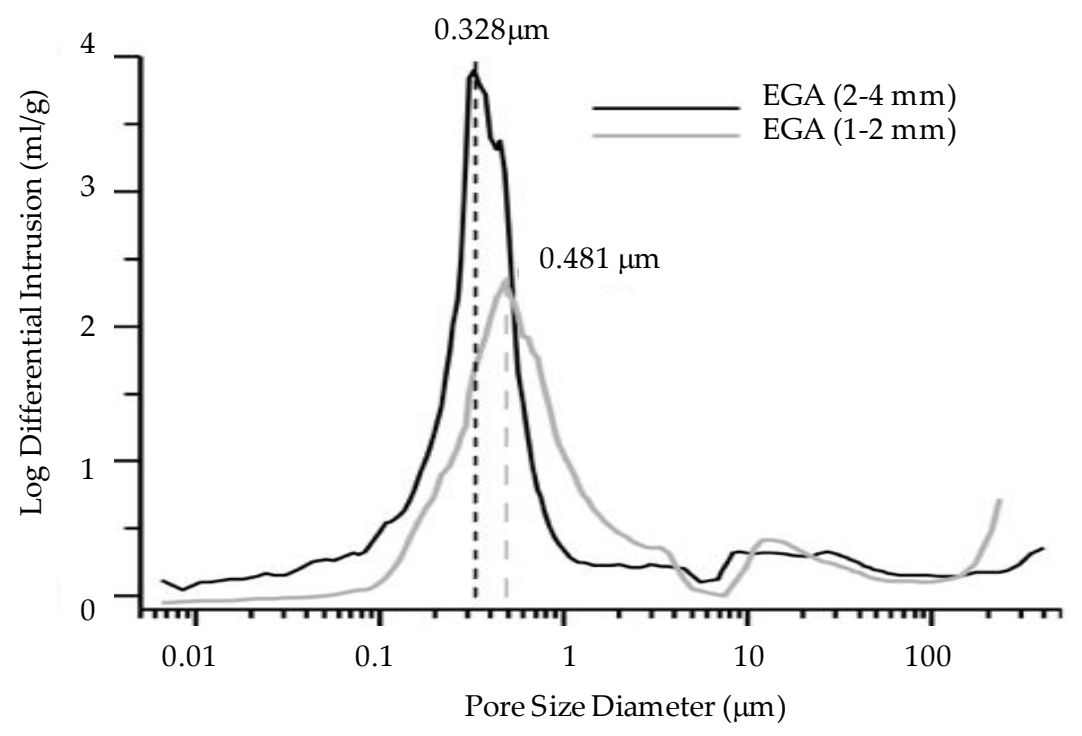

Figure 4. Pore size distribution of the EGA.

\subsection{Sample Preparation}

The mixes had a water to cement ratio of 0.4 and a sand to cement ratio of 3:1. Two set of mixes were prepared: the first set of mixes were fabricated by partial and full replacement of NA with EGA without inclusion of $\mathrm{nTiO}_{2}$. The designed mixes with $0 \%, 50 \%$, and $100 \%$ replacement percentage of EGA implied with CS, E50, and E100, respectively. The second set of mixes was fabricated by partial and full replacement of NA with EGA and incorporation of $1 \% \mathrm{nTiO}_{2}$. The designed mixes with incorporation of $\mathrm{TiO}_{2}$ and the EGA replacement percentage of $0 \%, 50 \%$, and $100 \%$ defined as CT, E50T, and E100T, respectively.

To fabricate the mixes, the dry materials (cement and NA/EGA) were placed in the mixer and mixed on the low speed for $2.0 \mathrm{~min}$. In the case of CT, E50T, and E100T mixes, the $\mathrm{nTiO}_{2}$ were sonicated for $15 \mathrm{~min}$ in the solution of water and superplasticizer (SP) [39]. Then the dispersed $n \mathrm{niO}_{2} / \mathrm{SP} /$ water solution was added slowly to the mix and the materials were mixed for another $5 \mathrm{~min}$. The mixes cast in $70 \times 70 \times 70 \mathrm{~mm}^{3}$ cubes and demolded after $24 \mathrm{~h}$. The samples were cured in the fog room at a constant temperature of $23^{\circ} \mathrm{C}$ and in accordance with AS1012.8. Table 3 demonstrates the mix proportion of the samples. The abbreviations for labeling each mix are defined in a way that the letters $\mathrm{C}$ and $\mathrm{E}$ representing control sample and mortar sample containing EGA respectively and number after the letters presents the percentage of NA replacement with EGA into the mixture. The letter $\mathrm{T}$ demonstrates the presence of $\mathrm{TiO}_{2}$ in the mix. For instance, the E50T mixture represents the sample that contains $50 \%$ EGA and $\mathrm{TiO}_{2}$.

Table 3. Mix proportion of the samples $\left(\mathrm{kg} / \mathrm{m}^{3}\right)$ of mortar.

\begin{tabular}{ccccccc}
\hline Composite ID & NA & EGA & Cement & Water & S.P & nTiO $_{\mathbf{2}}$ \\
\hline CS & 1750 & 0 & 525 & 233 & 11.7 & - \\
CT & 1750 & 0 & 525 & 233 & 11.7 & $1 \%$ \\
E50 & 875 & 133 & 525 & 233 & 8.8 & - \\
E50T & 875 & 133 & 525 & 233 & 8.8 & $1 \%$ \\
E100 & 0 & 267 & 525 & 233 & 5.8 & - \\
E100T & 0 & 267 & 525 & 233 & 5.8 & $1 \%$ \\
\hline
\end{tabular}

\subsection{Experimental Tests}

The flow table test was undertaken on the fresh cement mortar samples in accordance to the AS2701 to measure the mixtures workability and consistency. Moreover, the density of the mixture was determined via the density test according to AS2701. To measure the water penetration of the 
specimens, the water absorption test was conducted in accordance with AS1012.21 at the age of 28 days. The compressive test was undertaken on the cube specimens with the size of $70 \mathrm{~mm} \times 70 \mathrm{~mm} \times 70 \mathrm{~mm}$ and in accordance with AS1012.9 at the age of 7, 14, and 28 days. For each test, three samples were tested and the average including the error bar were reported.

In this study, the thermal insulation property and heat transfer rate of cement mortar containing EGA was evaluated by measuring the surface temperature distribution using infrared thermal imaging camera. For this purpose, the specimens with the dimension of $70 \mathrm{~mm} \times 70 \mathrm{~mm} \times 30 \mathrm{~mm}$ were prepared and kept at about $27^{\circ} \mathrm{C}$ for a few hours to allow all samples to achieve the same initial temperature. Then the samples were exposed to a heat source and the surface temperature distribution of the other side was captured by an infrared thermal camera for 15 min (Testo 872, Testo Australia). The thermal test was repeated for three times for each sample. Figure 5 illustrates a schematic diagram of the thermal test.

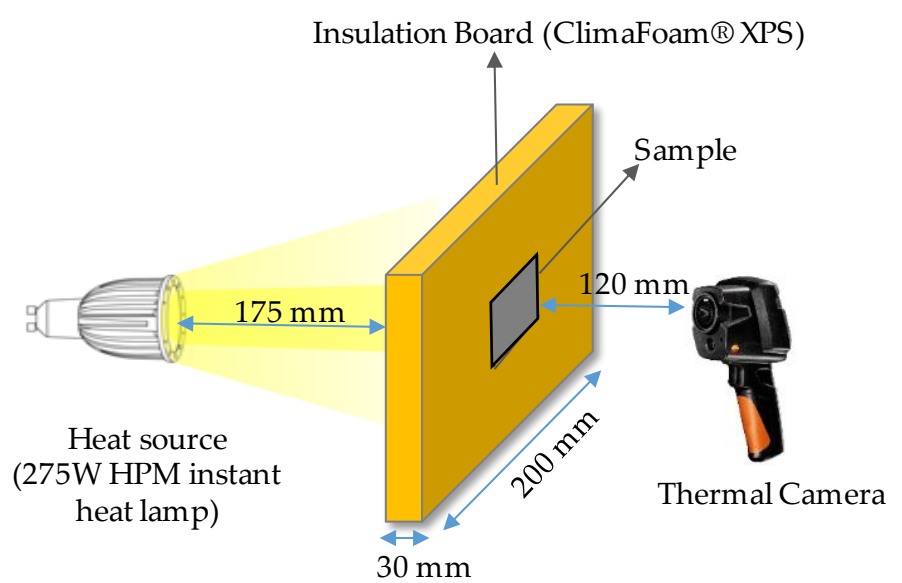

Figure 5. Infrared thermography test.

\section{Results and Discussion}

\subsection{Workability}

Figure 6 shows the flow table test and the flow table test results are presented in Table 4. The flow table test values were determined by averaging the diameters of each mixes test. All mixes showed flow values in the range of $140-215 \mathrm{~mm}$, without segregation or bleeding. The results revealed that addition of EGA increased the workability of cement mortar up to $26.6 \%$ and $41.25 \%$ for the E50 and E100 mixes respectively compared to the control mix (CS). The increment trend in workability despite the decreasing on the amount of superplasticizer in E50 and E100 mixes is contributed to the smooth surface and spherical shape of EGA [40-42]. Adding to this, the increase in the flow values can be due to the increase in the amount of entrapped air voids. Furthermore, the workability of CT, E50T, and E100T mixes increased by 5.35\%, 30.4\%, and 53.7\% respectively in comparison to the CS, E50, and E100 mixes respectively, which is attributed to the induction of the microbubble in the water solution during the sonication process and consequently increased in small air voids in the mixes.

Table 4. Flow results of mixes.

\begin{tabular}{cc}
\hline Mix ID & Average Flow Diameter $(\mathbf{m m})$ \\
\hline CS & 140.0 \\
E50 & 177.3 \\
E100 & 201.3 \\
CT & 147.5 \\
E50T & 182.5 \\
E100T & 215.3 \\
\hline
\end{tabular}




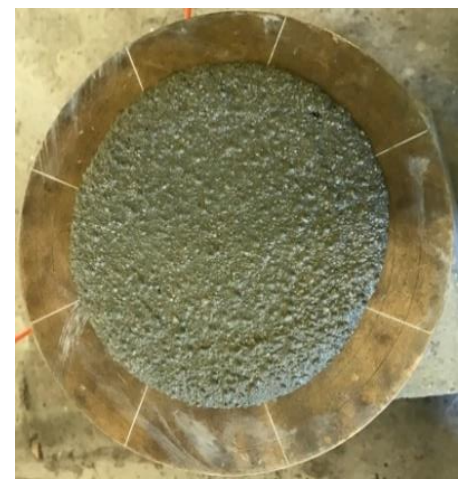

Figure 6. Flow table test.

\subsection{Density}

The density of the samples was measured, and the results are demonstrated in Figure 7. The measurement revealed the density of 2354,1769 , and $987 \mathrm{~kg} / \mathrm{m}^{3}$ for C.S, E50, and E100 respectively. It shows the density of E50 and E100 decreased $30 \%$ and $65 \%$ respectively in comparison to the CS, which is attributed to the very low density of EGA and its porous structure. In addition, the densities of CT, E50T, and E100T were 2\%, 3\%, and 6\% higher than CS, E50, and E100 respectively. It can be concluded that the increase in density was attributed to the lower porosity in the cement matrix due to the incorporation of $\mathrm{nTiO}_{2}$. It is noteworthy that $\mathrm{E} 100$ with density of $987 \mathrm{~kg} / \mathrm{m}^{3}$ was classified as a lightweight mortar that can be used for production of lightweight concrete. Figure 8 illustrates the cross section of CS and E100 samples.

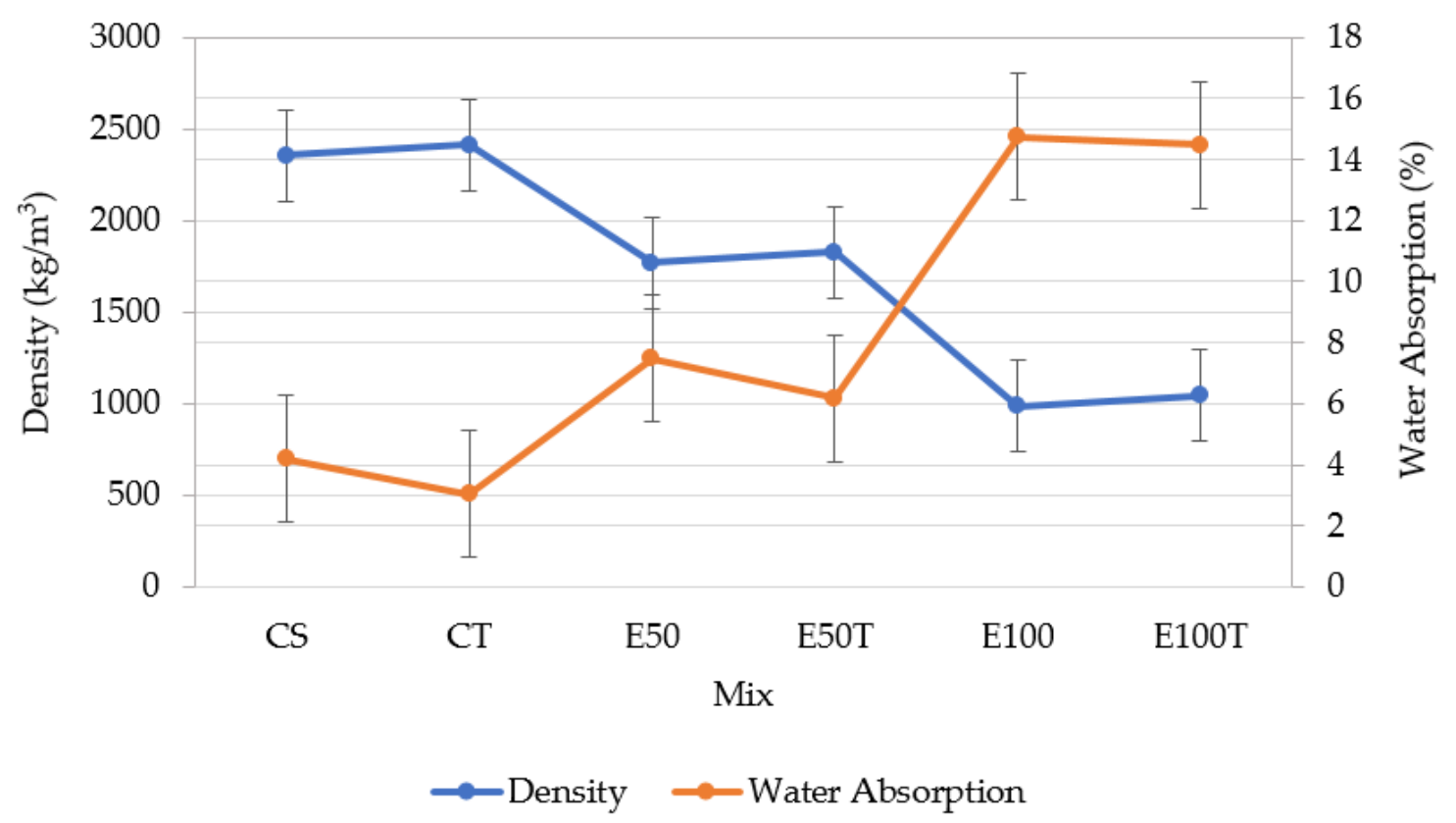

Figure 7. Density and water absorption of mix specimens.

\subsection{Water Absorption}

The water absorption test was completed on all mixes and the results are shown in Figure 7. The water absorption of $4.19 \%$ obtained for control sample (CS) however a higher water absorption rate was obtained for the mixes containing EGA. The water absorption of E50 and E100 mixes were 7.47\% and $14.74 \%$ respectively, which shows a $78 \%$ and $252 \%$ increase in the permeability of the matrix, compared to the control sample. The increase in water absorption is due to the high porosity of EGA in comparison to NA. The results revealed that the water penetration increased by increasing the EGA 
content. The water absorption rate obtained for the E100 (values of approximately 14\%) was higher than the acceptable range $(<10 \%)[43,44]$. The addition of $\mathrm{nTiO}_{2}$ reduced the water absorption value by $28 \%, 17 \%$, and $2 \%$ for samples containing $0 \%, 50 \%$, and $100 \%$ EGA respectively. The decrease in water absorption upon the inclusion of $\mathrm{nTiO}_{2}$ coincides with previous studies [45] and aligns with the density results. The reduction in water absorption was attributed to the filling effect of $\mathrm{nTiO}_{2}$ and reducing the porosity of the cement matrix. It is worthy to note that the sonication process resulted in tiny bubbles of air uniformly distributed in the mortar. These small bubbles are like entraining air that improves the workability of the mixes. Indeed, $\mathrm{nTiO}_{2}$ acted as nanofillers in mortar and improved the resistance to water penetration of the cement composite [46].

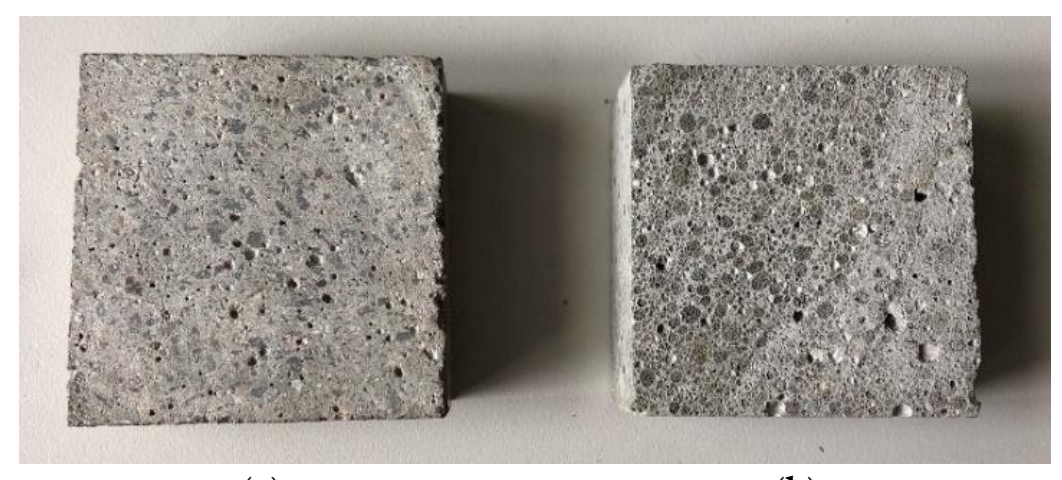

(a)

(b)

Figure 8. Cross-section of (a) the control sample (CS) and (b) E100 mixtures samples with uniform distribution of EGA in the cement matrix.

\subsection{Compressive Strength}

The experimental test for compressive strength was carried out at different curing ages of 7, 14, and 28 days. Figure 9 shows the impact of EGA and $\mathrm{TiO}_{2}$ inclusion on the compressive strength of the mortar composites at different ages. It is observed that the inclusion of the EGA significantly decreased the compressive strength of cement mortar. The results of 28-day compressive strength demonstrated that $50 \%$ replacement of NA with EGA reduced the strength about $65.8 \%$ in compare to the control sample (C.S). In addition, it was observed that as the EGA content increased from $50 \%$ to $100 \%$, the compressive strength dropped dramatically from 26.25 to $8.20 \mathrm{MPa}$ at the age of 28 days. It is noteworthy that the compressive strength was still in the acceptable range and similar or higher than reported results in the literature [21,25]. Namsone et al. [25] reported the 28-day compressive of 5.7 MPa for a foamed matrix using EGA and obtained the compressive strengths of 6.68-12.49 MPa for the EGA cement mortar. Indeed, the samples containing $100 \% \mathrm{EGA}$ without $\mathrm{nTiO}_{2}$ had the lowest compressive strength out of all the mixes.

Furthermore, the results indicated a normal increasing trend for the compressive strength for CS, $\mathrm{E} 50$, and $\mathrm{E} 100$ mixes as the curing process progresses. However, the mixes containing $\mathrm{nTiO}_{2}$ revealed a relatively different strength development tend. It was revealed that CT, E50T, and E100T mixes reached to $84.6 \%, 87.2 \%$, and $77.2 \%$ of maximum strength within 7 days of curing while for samples without $\mathrm{nTiO}_{2}$ (CS, E50, and E100 mixes) it happened at 14 days of curing. This behavior was attributed to the addition of $\mathrm{nTiO}_{2}$ into the cementitious materials, which resulted in an accelerated rate of hydration process. A similar attribute has been reported in previous studies that when $\mathrm{nTiO}_{2}$ is uniformly distributed throughout the matrix, the hydration process and formation of C-S-H gel is accelerated, which results in early strength $[32,47,48]$. In the other set of mixes, the effect of $\mathrm{nTiO}_{2}$ inclusion on the compressive strength of mixes was investigated after a different curing time. The compressive strength results of E50T and E100T mixes at 28 days showed the similar trend. It was observed that the addition of EGA significantly decreased the compressive strength and the strength significantly dropped as the EGA content increased however, inclusion of $\mathrm{nTiO}_{2}$ compensated some part of the compressive 
strength. The average compressive strength at 28 days of CT, E50T, and E100T mixes were 76.72, 29.70, and 11.4 MPa respectively, which shows $1.7 \%, 13.1 \%$, and $39.0 \%$ enhancement in comparison to CS, E50, and E100 mixes respectively. It can be concluded that $\mathrm{nTiO}_{2}$ acts as nanofillers in specimens and recovers their pore structure by decreasing voids and pores in the composite matrix [46].

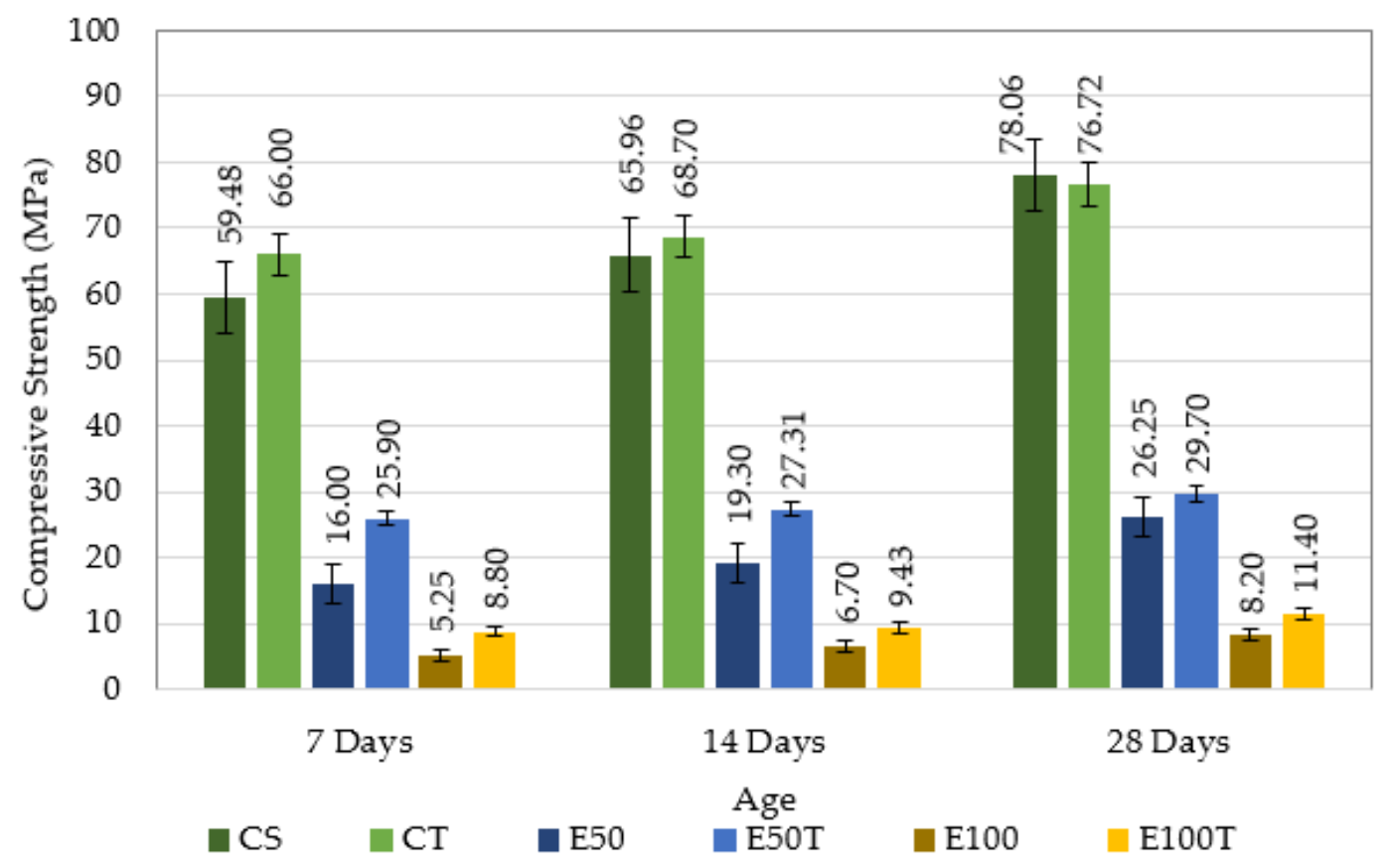

Figure 9. Compressive strength of samples at different ages.

In summary it can be concluded that the compressive strength and water absorption of concrete are highly influenced by the density of the mix. The results revealed an interrelationship between density and compressive strength. It was observed that the compressive strength dropped by decrement of the sample's density (CS, E50, and E100 mixes). Similarly, an increase in density for CT, E50T, and E100T mixes resulted in an increase in compressive strength compared to CS, E50, and E100 mixes respectively. Moreover, the results demonstrated an inverse relation between density and water absorption. It was found that water absorption increased by decreasing the density of the mixes in case of CS, E50, and E100. However, the water absorption decreased by integration of $\mathrm{TiO} 2$ into the mixes (CT, E50T, and $\mathrm{E} 100 \mathrm{~T})$ and increment of density due to a lower porosity of the matrix.

\subsection{Infrared Thermography}

In order to evaluate the thermal insulating properties of the cement composites, the infrared thermography (IRT) experiment was carried out on all the samples: CS, E50, E100, CST, E50T, and E100T. Figure 10 illustrates the thermal images of surface temperature distribution of the samples captured by the IRT camera at different heating times. According to the relationship between the color and temperature value, it can be suggested that the heat-transferring rate and thermal conductivity of cement composites were significantly decreased with the inclusion of EGA. The thermal images clearly demonstrate a different temperature distribution in the control sample (CS mix) and the samples containing EGA (E50 and E100 mixes). The results show that the temperature increased rapidly in the CS however, a noticeable slower heat transfer rate observed for samples incorporated with EGA (E50 and E100). The data also revealed a drop in the heat transfer rate as the EGA content increased. For instance, after $15 \mathrm{~min}$ the average surface temperature in the $\mathrm{CS}$ sample reached $55^{\circ} \mathrm{C}$ while the average surface temperature in the E50 and E100 samples reached 52.7 and $48.7^{\circ} \mathrm{C}$ respectively, which shows a temperature difference of $2.3^{\circ} \mathrm{C}$ and $6.0^{\circ} \mathrm{C}$ for E50 and E100 respectively. Moreover, the results demonstrated the heat transfer rate of $1.75,1.60$, and $1.35^{\circ} \mathrm{C} / \mathrm{min}$ for CS, E50, and E100 respectively that shows a lower rate for samples 
containing EGA (E50 and E100) in comparison to the control sample (CS). This observation was attributed to a high porosity and low thermal conductivity of EGA. Indeed, by incorporation of EGA the air void is replaced with sand, which has a high thermal conductivity. EGA has a thermal conductivity of $0.07 \mathrm{~W} / \mathrm{mK}$ that is much less than that of sand (Expanded Glass Technologies). Consequently, by replacing the NA with EGA the heat transfer of the cement composite was reduced.

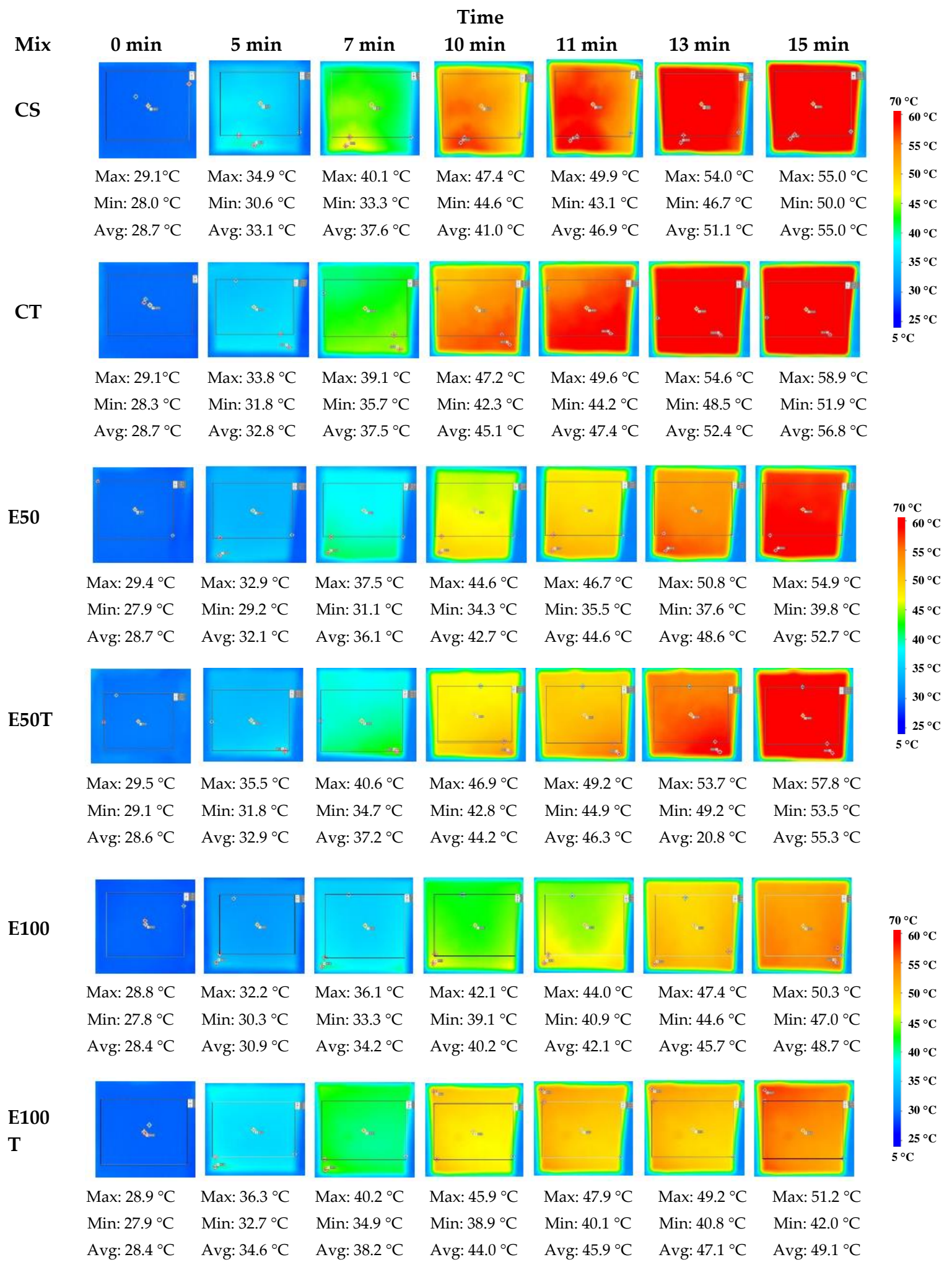

Figure 10. Infrared thermography images of different samples. 
Table 5 demonstrates the average temperature differences for each mix. The thermal charging results for the samples inclusion $\mathrm{nTiO}_{2}$ showed a different trend to the first set of mixes (mixes without $\mathrm{nTiO}_{2}$ ). It was observed that incorporation $\mathrm{nTiO}_{2}$ increased the heat transfer rate, which is undesired in terms of thermal insulation properties. The thermal images demonstrated that inclusion of $\mathrm{nTiO}_{2}$ into the composite increased the heat transfer rate compared to the samples without $\mathrm{nTiO}_{2}$. For example, after 15 min the average surface temperature in CS, E50, and E100 samples reached to $55^{\circ} \mathrm{C}, 52.7^{\circ} \mathrm{C}$, and $48.7^{\circ} \mathrm{C}$ respectively. While average surface temperature in the CT, E50T, and E100T samples reached to $56.8^{\circ} \mathrm{C}, 55^{\circ} \mathrm{C}$, and $49.1^{\circ} \mathrm{C}$ respectively that shows an increase in the temperature difference of $1.6^{\circ} \mathrm{C}, 2.3^{\circ} \mathrm{C}$, and $1.4^{\circ} \mathrm{C}$ respectively. Furthermore, the results demonstrated the heat transfer rate of $1.87,1.76$, and $1.38^{\circ} \mathrm{C} / \mathrm{min}$ for $\mathrm{CT}$, E50T, and E100T respectively that indicates higher rate than the samples without $\mathrm{nTiO}_{2}$. It can be concluded that $\mathrm{nTiO}_{2}$ acts as a filler and changes the pore structures of the cement composite and consequently the thermal charging performance of the matrix. Therefore, in terms of thermal properties, NA substitution with EGA improves the thermal insulation properties of cement composites. This positive effect is attributed to lower thermally conductive and higher porosity of EGA compared to NA.

Table 5. The average temperature differences for each mix.

\begin{tabular}{ccccccc}
\hline \multirow{2}{*}{ Mix } & \multicolumn{3}{c}{$\boldsymbol{\Delta}\left(\mathbf{T}_{\text {ave. }}\right)$} & \multicolumn{3}{c}{ Heat Transfer Rate $\left({ }^{\circ} \mathbf{C} / \mathbf{m i n}\right)$} \\
\cline { 2 - 7 } & $\mathbf{5} \mathbf{~} \mathbf{m i n}$ & $\mathbf{1 0} \mathbf{~} \mathbf{i n}$ & $\mathbf{1 5} \mathbf{~}$ in & $\mathbf{5} \mathbf{~}$ in & $\mathbf{1 0} \mathbf{~} \mathbf{i n}$ & $\mathbf{1 5} \mathbf{~}$ in \\
\hline CS & 4.40 & 12.30 & 26.30 & 1.58 & 2.80 & 1.75 \\
CT & 4.10 & 16.40 & 28.10 & 2.46 & 2.34 & 1.87 \\
E50 & 3.40 & 14.00 & 24.00 & 2.12 & 2.00 & 1.60 \\
E50T & 4.30 & 15.60 & 26.40 & 2.26 & 2.16 & 1.76 \\
E100 & 2.50 & 11.80 & 20.30 & 1.86 & 1.70 & 1.35 \\
E100T & 6.20 & 15.60 & 20.70 & 1.88 & 1.02 & 1.38 \\
\hline
\end{tabular}

\section{Conclusions}

This experimental work investigated the physical properties as well as the thermal insulation property of cement mortar containing EGA and $\mathrm{TiO}_{2}$. The findings revealed that incorporating EGA into the mortar composite causing a significant decrease in density and compressive strength, which was attributed to the porous nature and low compressive strength of EGA. The results also demonstrated that as the EGA content increased, the workability and water absorption of cement composite increased. It is found that the increase in water absorption was due to the high porosity of EGA in comparison to NA. However, the beneficial effect of the EGA was the decrease in the heat-transferring rate of the cement composite, which indicates the feasibility of a potential reduction in energy consumption in buildings. Moreover, the results demonstrated that inclusion of $\mathrm{TiO}_{2}$ into the cement composite partially compensated the water absorption and loss in compressive strength. However, it was revealed that addition of $\mathrm{nTiO}_{2}$ into EGA-cement composites increased the heat transfer rate of the cement matrix and insulation properties as $\mathrm{nTiO}_{2}$ acts as nanofillers and changes the pores structure in the cement matrix. It can be concluded that in terms of thermal behavior, substitution of NA with EGA decreases the heat transfer rate and consequently improves the thermal insulation properties of the cement mortar.

Author Contributions: Conceptualization, A.Y., W.T.; methodology, W.T., M.K., S.W. and C.F.; Investigation, W.T., M.K. and A.Y.; writing-original draft preparation, A.Y., M.K.; writing-review and editing, W.T., C.F., M.K., S.W. and A.Y. All authors have read and agree to the published version of the manuscript.

Funding: This research received no external funding.

Acknowledgments: The authors gratefully acknowledge the financial support provided by University of Newcastle (2017 UNIPRS and UNRS Central Scholarship). We also thank the support and cooperation of the staff of the concrete laboratory at the School of Civil Engineering, University of Newcastle, and Expanded Glass Technologies Pty Ltd. for providing EGA for this experimental investigation. 
Conflicts of Interest: The author declares no conflict of interest.

\section{References}

1. Chung, O.; Jeong, S.G.; Kim, S. Preparation of energy efficient paraffinic PCMs/expanded vermiculite and perlite composites for energy saving in buildings. Sol. Energy Mater. Sol. Cells 2015, 137, 107-112. [CrossRef]

2. Rao, V.V.; Parameshwaran, R.; Ram, V.V. PCM-mortar based construction materials for energy efficient buildings: A review on research trends. Energy Build. 2018, 158, 95-122. [CrossRef]

3. Krishnamoorthy, R.R.; Zujip, J.A. Thermal conductivity and microstructure of concrete using recycle glass as a fine aggregate replacement. Int. J. Emerg. Technol. Adv. Eng. 2013, 3, 463-471.

4. Real, S.; Gomes, M.G.; Moret Rodrigues, A.; Bogas, J.A. Contribution of structural lightweight aggregate concrete to the reduction of thermal bridging effect in buildings. Constr. Build. Mater. 2016, 121, 460-470. [CrossRef]

5. Roberz, F.; Loonen, R.C.G.M.; Hoes, P.; Hensen, J.L.M. Ultra-lightweight concrete: Energy and comfort performance evaluation in relation to buildings with low and high thermal mass. Energy Build. 2017, 138, 432-442. [CrossRef]

6. Sibahy, A.A.; Edwards, R. Thermal behaviour of novel lightweigh concrete at ambient and elevated temperatures: Experimental, modelling and parametric studies. Constr. Build. Mater. 2012, 31, $174-187$. [CrossRef]

7. Al-Zubaid, A.B.; Shabeeb, K.M.; Ali, A.I. Study the effect of recycled glass on the mechanical properties of green concrete. Energy Procedia 2017, 119, 680-692. [CrossRef]

8. Park, S.B.; Lee, B.C.; Kim, J.H. Studies on mechanical properties of concrete containing waste glass aggregate. Cem. Concr. Res. 2004, 34, 2181-2189. [CrossRef]

9. Islam, G.M.S.; Rahman, M.H.; Kazi, N. Waste glass powder as partial replacement of cement for sustainable concrete practice. Int. J. Sustain. Built Environ. 2017, 6, 37-44. [CrossRef]

10. Aliabdo, A.A.; Abd Elmoaty, A.E.M.; Aboshama, A.Y. Utilization of waste glass powder in the production of cement and concrete. Constr. Build. Mater. 2016, 124, 866-877. [CrossRef]

11. Afshinnia, K.; Rangaraju, P.R. Efficiency of ternary blends containing fine glass powder in mitigating alkali-silica reaction. Constr. Build. Mater. 2015, 100, 234-245. [CrossRef]

12. Yun, T.S.; Jeong, Y.J.; Han, T.S.; Youm, K.S. Evaluation of thermal conductivity for thermally insulated concretes. Energy Build. 2013, 61, 125-132. [CrossRef]

13. Chung, S.Y.; Abd Elrahman, M.; Sikora, P.; Rucinska, T.; Horszczaruk, E.; Stephan, D. Evaluation of the effects of crushed and expanded waste glass aggregates on the material properties of lightweight concrete using image-based approaches. Materials 2017, 10, 1354. [CrossRef]

14. Chung, S.Y.; Han, T.S.; Kim, S.Y.; Kim, J.H.J.; Youm, K.S.; Lim, J.H. Evaluation of effect of glass beads on thermal conductivity of insulating concrete using micro CT images and probability functions. Cem. Concr. Compos. 2016, 65, 150-162. [CrossRef]

15. Ez-zaki, H.; El Gharbi, B.; Diouri, A. Development of eco-friendly mortars incorporating glass and shell powders. Constr. Build. Mater. 2018, 159, 198-204. [CrossRef]

16. Abd Elrahman, M.; Chung, S.Y.; Stephan, D. Effect of different expanded aggregates on the properties of lightweight concrete. Mag. Concr. Res. 2018, 71, 95-107. [CrossRef]

17. Yu, Q.L.; Spiesz, P.; Brouwers, H.J.H. Ultra-lightweight concrete: Conceptual design and performance evaluation. Cem. Concr. Compos. 2015, 61, 18-28. [CrossRef]

18. Yu, R.; van Onna, D.V.; Spiesz, P.; Yu, Q.L.; Brouwers, H.J.H. Development of ultra-lightweight fibre reinforced concrete applying expanded waste glass. J. Clean. Prod. 2016, 112, 690-701. [CrossRef]

19. Šeputytė-Jucikè, J.; Sinica, M. The effect of expanded glass and polystyrene waste on the properties of lightweight aggregate concrete. Eng. Struct. Technol. 2016, 8, 31-40. [CrossRef]

20. Maddalena, C.; Luca, B. Durability of lightweight concrete with expanded glass and silica fume. Mater. J. 2017, 114. [CrossRef]

21. Rumsys, D.; Spudulis, E.; Bacinskas, D.; Kaklauskas, G. Compressive strength and durability properties of structural lightweight concrete with fine expanded glass and/or clay aggregates. Materials 2018, 11, 2434. [CrossRef] [PubMed] 
22. Bogas, J.A.; Gomes, A.; Pereira, M. Self-compacting lightweight concrete produced with expanded clay aggregate. Constr. Build. Mater. 2012, 35, 1013-1022. [CrossRef]

23. Yu, Q.; Spiesz, P.; Brouwers, H. Development of cement-based lightweight composites-Part 1: Mix design methodology and hardened properties. Cem. Concr. Compos. 2013, 44, 17-29. [CrossRef]

24. Spiesz, P.; Yu, Q.; Brouwers, H. Development of cement-based lightweight composites-Part 2: Durabilityrelated properties. Cem. Concr. Compos. 2013, 44, 30-40. [CrossRef]

25. Namsone, E.; Sahmenko, G.; Namsone, E.; Korjakins, A. Thermal conductivity and frost resistance of foamed concrete with porous aggregate, Environment. Technology. Resources. In Proceedings of the 11th International Scientific and Practical Conference, Rezekne, Latvia, 15-17 June 2017; Volume 3, pp. 222-228.

26. Kurpińska, M.; Ferenc, T. Effect of porosity on physical properties of lightweight cement composite with foamed glass aggregate. In Proceedings of the II International Conference of Computational Methods in Engineering Science (CMES'2017), Lublin, Poland, 23-25 November 2017; p. 06005.

27. Kurpinska, M.; Kułak, L. Predicting performance of lightweight concrete with granulated expanded Glass and Ash aggregate by means of using Artificial Neural Networks. Materials 2019, 12, 2002. [CrossRef]

28. Lee, G.; Poon, C.S.; Wong, Y.L.; Ling, T.C. Effects of recycled fine glass aggregates on the properties of dry-mixed concrete blocks. Constr. Build. Mater. 2013, 38, 638-643. [CrossRef]

29. Penacho, P.; Brito, J.D.; Rosário Veiga, M. Physico-mechanical and performance characterization of mortars incorporating fine glass waste aggregate. Cem. Concr. Compos. 2014, 50, 47-59. [CrossRef]

30. Lucas, S.S.; Ferreira, V.M.; de Aguiar, J.L.B. Incorporation of titanium dioxide nanoparticles in mortarsInfluence of microstructure in the hardened state properties and photocatalytic activity. Cem. Concr. Res. 2013, 43, 112-120. [CrossRef]

31. Behfarnia, K.; Azarkeivan, A.; Keivan, A. The effects of $\mathrm{TiO}_{2}$ and $\mathrm{ZnO}$ nanoparticles on physical and mechanical properties of normal concrete. Asian J. Civ. Eng. (Bhrc) 2013, 14, 517-531.

32. Ma, B.; Li, H.; Mei, J.; Li, X.; Chen, F. Effects of nano-TiO ${ }_{2}$ on the toughness and durability of cement-based material. Adv. Mater. Sci. Eng. 2015, 2015, 583106. [CrossRef]

33. Sorathiya, J.; Shah, S.; Kacha, M.S. Effect on addition of nano "titanium dioxide" $\left(\mathrm{TiO}_{2}\right)$ on compressive strength of cementitious concrete. Kalpa Publ. Civ. Eng. 2017, 1, 219-225.

34. Khushwaha, A.; Saxena, R.; Pal, S. Effect of titanium dioxide on the compressive strength of concrete. J. Civ. Eng. Environ. Technol. 2015, 2, 482-486.

35. Grebenisan, E.; Hegyi, A.; Szilágyi, H. A review on developing self-cleaning cementitious materials. Constructii 2018, 19, 37-43.

36. Nazari, A.; Riahi, S.; Riahi, S.; Shamekhi, S.F.; Khademno, A. Assessment of the effects of the cement paste composite in presence $\mathrm{TiO}_{2}$ nanoparticles. J. Am. Sci. 2010, 6, 43-46.

37. Nazari, A.; Riahi, $\mathrm{S}$. $\mathrm{TiO}_{2}$ nanoparticles' effects on properties of concrete using ground granulated blast furnace slag as binder. Sci. China Technol. Sci. 2011, 54, 3109. [CrossRef]

38. Cui, H.; Feng, T.; Yang, H.; Bao, X.; Tang, W.; Fu, J. Experimental study of carbon fiber reinforced alkali-activated slag composites with micro-encapsulated PCM for energy storage. Constr. Build. Mater. 2018, 161, 442-451. [CrossRef]

39. Yousefi, A.; Bunnori, N.M.; Khavarian, M.; Hassanshahi, O.; Majid, T.A. Experimental investigation on effect of multi-walled carbon nanotubes concentration on flexural properties and microstructure of cement mortar composite. In Proceedings of the International Conference of Global Network for Innovative Technology (IGNITE) and AWAM International Conference in Civil Engineering (AICCE) 2017, Penang, Malaysia, 8-10 August 2017; AIP Conference Proceedings. AIP Publishing: Melville, NY, USA, 2017; p. 020032. [CrossRef]

40. Ling, T.C.; Poon, C.S.; Kou, S.C. Influence of recycled glass content and curing conditions on the properties of self-compacting concrete after exposure to elevated temperatures. Cem. Concr. Compos. 2012, 34, 265-272. [CrossRef]

41. Sharifi, Y.; Houshiar, M.; Aghebati, B. Recycled glass replacement as fine aggregate in self-compacting concrete. Front. Struct. Civ. Eng. 2013, 7, 419-428. [CrossRef]

42. Wright, J.R.; Cartwright, C.; Fura, D.; Rajabipour, F. Fresh and hardened properties of concrete incorporating recycled glass as 100\% sand replacement. J. Mater. Civ. Eng. 2013, 26, 04014073. [CrossRef]

43. Medina, C.; Zhu, W.; Howind, T.; de Rojas, M.I.S.; Frías, M. Influence of mixed recycled aggregate on the physical-mechanical properties of recycled concrete. J. Clean. Prod. 2014, 68, 216-225. [CrossRef] 
44. Borhan, M.; Mohamed Sutan, N. Laboratory study of water absorption of modified mortar. Unimas E J. Civ. Eng. 2011, 2, 25-30.

45. Qudoos, A.; Kim, H.; Ryou, J.S. Influence of titanium dioxide nanoparticles on the sulfate attack upon ordinary Portland cement and slag-blended mortars. Materials 2018, 11, 356.

46. Nazari, A.; Riahi, S. The effect of $\mathrm{TiO}_{2}$ nanoparticles on water permeability and thermal and mechanical properties of high strength self-compacting concrete. Mater. Sci. Eng. A 2010, 528, 756-763. [CrossRef]

47. Nehdi, M.; Soliman, A.M. Early-age properties of concrete: Overview of fundamental concepts and state-of-the-art research. Proc. Inst. Civ. Eng. Constr. Mater. 2011, 164, 57-77. [CrossRef]

48. Lee, B.Y.; Jayapalan, A.R.; Kurtis, K.E. Effects of nano- $\mathrm{TiO}_{2}$ on properties of cement-based materials. Mag. Concr. Res. 2013, 65, 1293-1302. [CrossRef]

(C) 2020 by the authors. Licensee MDPI, Basel, Switzerland. This article is an open access article distributed under the terms and conditions of the Creative Commons Attribution (CC BY) license (http://creativecommons.org/licenses/by/4.0/). 